\title{
Copper-Metalized GaAs pHEMT with Cu/Ge Ohmic Contacts
}

\author{
E. V. Anichenko, ${ }^{1}$ V. S. Arykov, ${ }^{1}$ E. V. Erofeev, ${ }^{1}$ and V. A. Kagadei $^{2}$ \\ ${ }^{1}$ Microelectronics Department, Research and Production Company "Micran", 47 Vershinina Street, Tomsk 634045, Russia \\ ${ }^{2}$ RF Electronics Department, Submicron Technologies, 8 Akademicheskiy Avenue, Tomsk 634021, Russia
}

Correspondence should be addressed to E. V. Erofeev, erofeev@sibmail.com

Received 29 November 2010; Accepted 1 March 2011

Academic Editor: Rüdiger Quay

Copyright ( 92012 E. V. Anichenko et al. This is an open access article distributed under the Creative Commons Attribution License, which permits unrestricted use, distribution, and reproduction in any medium, provided the original work is properly cited.

The fully Cu-metalized GaAs pHEMT using developed $\mathrm{Cu} / \mathrm{Ge}$-based ohmic contacts and T-gate Ti/Mo/Cu with length of the $150 \mathrm{~nm}$ has been successfully fabricated for the high-frequency applications. The fabricated Cu-metalized pHEMT has a maximum drain current of $360 \mathrm{~mA} / \mathrm{mm}$, an off-state gate-drain breakdown of $7 \mathrm{~V}$, and a transconductance peak of $320 \mathrm{mS} / \mathrm{mm}$ at $V_{\mathrm{ds}}=3 \mathrm{~V}$. The maximum stable gain value was about $15 \mathrm{~dB}$ at frequency $10 \mathrm{GHz}$. The current gain cutoff frequency of the copper-metalized device is about $60 \mathrm{GHz}$ at $V_{\mathrm{ds}}=3 \mathrm{~V}$, and maximum frequency of oscillations is beyond $100 \mathrm{GHz}$. This work investigated in detail the formation of $\mathrm{Cu} / \mathrm{Ge}$ ohmic contacts to $n$-GaAs with an atomic hydrogen preannealing step. It was shown that after the first preliminary annealing is carried out in a flow of atomic hydrogen with a flow density of atoms of $10^{13} / 10^{16}$ at. $\mathrm{cm}^{2} \mathrm{~s}^{-1}$ a reduction in specific contact resistance by $2 / 2.5$ times is observed. The reduction in specific contact resistance is apparently caused by the action of the hydrogen atoms which minimise the rate of the oxidizing reactions and activate solid phase reactions forming the ohmic contact during the thermal treatment process.

\section{Introduction}

Wafer production cost is an important metric that measures the profitability and success of a semiconductor fab. The current economic situation has driven the price of $\mathrm{Au}$ and Pt up steadily over the last couple of years. Although the precious metals prices are beyond one's control, with proper engineering, these metals can be replaced by a less expensive alternative-copper.

Copper metallization has been extensively used in the silicon integrated circuit technology since IBM announced its success in silicon very large scale integration processing [13]. The advantages of copper metallization for Si technology include lower resistivity and higher electromigration resistance. Even though the use of copper as metallization metal has become very popular in Si devices, there were very few reports of copper metallization of GaAs devices published in the literature [4-7]. The use of copper as the metallization metal instead of gold has several advantages such as lower resistivity, higher thermal conductivity, and lower cost. If $\mathrm{Cu}$ replaces $\mathrm{Au}$ as the metallization metal for the pHEMTs, then the resulting improvement in the electrical conductivity can increase the transmission speed of the circuits [8]. However, copper diffuses very fast into GaAs and is a deep acceptor, moreover, copper oxidized under atmosphere exposure, so copper metallization of GaAs device without a diffusion and passivation barriers degrades their electrical properties.

Other authors in [3] reported $\mathrm{Cu}$-metalized compound semiconductor pHEMT with $\mathrm{Pd} / \mathrm{Ge} / \mathrm{WN}_{x} / \mathrm{Cu}$ ohmic contacts a thickness of $500 \mathrm{~nm}, \mathrm{Ti} / \mathrm{Pt} / \mathrm{Cu}$ gate and $\mathrm{Cu}$-based interconnect air-bridge structure are presented. However, in the nanoscale-gate-length process, this thick $\mathrm{Pd} / \mathrm{Ge} / \mathrm{WN}_{x} / \mathrm{Cu}$ ohmic contact may induce a poor edge definition after alloying which can cause the problem such as gate misalignment and the use of precious metals such as Pt, Pd increases the cost of wafer production.

The formation of nonprecious Cu-based ohmic contact with good parameters is obviously the most important problem in $\mathrm{Cu}$-metalized GaAs pHEMT fabrication. In studies [9-11] it was established that on the basis of twolayer $\mathrm{Cu} / \mathrm{Ge}$ it is possible to form a contact of $\mathrm{Cu}_{3} \mathrm{Ge}$ with a low value of contact resistance, high thermal stability of the parameters, smooth surface structure, even edges of the contact pads, and also low production costs. It was shown 
that the ohmic behaviour was partly due to Ge occupation of Ga vacancies. Ge atoms can serve as donors and help to induce a heavily doped interfacial region which enhances tunnelling current.

The authors of study [12] proposed a two-stage annealing of the $\mathrm{Cu} / \mathrm{Ge}$ contact. The first stage of annealing (preliminary low-temperature annealing) was carried out under vacuum at a temperature of $100^{\circ} \mathrm{C}$ in situ with the deposition of contact metallization, and the second high-temperature annealing was carried out ex situ after completing the process of forming the contact pads patterns. The use of two-stage annealing enabled the contact resistance to be reduced to $6.5 \times 10^{-7} \mathrm{ohm} \mathrm{cm}^{2}$. Thus these studies [10-12] testify to the potential of using $\mathrm{Cu} / \mathrm{Ge}$ contacts in nanoscale GaAs MMIC technology.

The purposes of the present work are to develop and produce fully copper-metalized pHEMT with $\mathrm{Cu} / \mathrm{Ge}$-based ohmic contacts and $\mathrm{Ti} / \mathrm{Mo} / \mathrm{Cu} 150 \mathrm{~nm}$ T-gate; to investigate the possibility to improve the parameters of $\mathrm{Cu} / \mathrm{Ge}$ ohmic contacts by two-stage annealing with the first preliminary annealing being carried out in situ under vacuum, or in a flow of atomic hydrogen, and the second ex situ in a nitrogen atmosphere; and to investigate the DC and RF parameters of fabricated $\mathrm{Cu}$-metalized GaAs pHEMT.

\section{Experimental}

2.1. Fabrication of GaAs pHEMT. The fully Cu-metalized GaAs pHEMT was formed on the GaAs/AlGaAs/InGaAs pseudomorphic structures have been grown by using molecular beam epitaxy. A $30 \mathrm{~nm}$ thick undoped GaAs buffer layer and ten AlAs-GaAs superlattices are grown on 3inch diameter semiinsulating GaAs substrates, followed by a $60 \mathrm{~nm}$ undoped GaAs layer. The thickness of the $\mathrm{In}_{0.24} \mathrm{Ga}_{0.76}$ As channel layer is $10 \mathrm{~nm}$. The planar doping with a donor density of $5 \times 10^{12} \mathrm{~cm}^{-2}$ is separated from the active layer by a thin undoped $\mathrm{Al}_{0.22} \mathrm{Ga}_{0.78}$ As spacer and an undoped $\mathrm{Al}_{0.22} \mathrm{Ga}_{0.78}$ As Schottky layer is grown. To reduce parasitic resistance, the GaAs cap layer is highly doped with a concentration of $5 \times 10^{18} \mathrm{~cm}^{-3}$.

After mesa isolation the source and drain ohmic metals were formed. $\mathrm{Cu} / \mathrm{Ge}(122 \mathrm{~nm} / 78 \mathrm{~nm})$ ohmic contacts deposition by the electron beam evaporation under a vacuum of $1 \times 10^{-6}$ torr was used. After the ohmic contact structure was formed using the liftoff method a rapid thermal annealing was carried out. Annealing was performed ex situ in a single high-temperature stage in a inert environment at a temperature range $T=200-500^{\circ} \mathrm{C}$ for a period of $t=3 \mathrm{~min}$.

$150 \mathrm{~nm} \mathrm{Ti} / \mathrm{Mo} / \mathrm{Cu}$ T-shape gates were fabricated by electron beam lithography and liftoff process. There was used a trilayer resist stack of 950 PMMA/LOR 5B/495 PMMA (from bottom to top). The resists were spin-coated onto the substrate. Each resist layer was baked for a $5 \mathrm{~min}$ at $180^{\circ} \mathrm{C}$ on the hotplate. The Raith- $150^{\text {TWO }}$ e-beam nanolithography system was used for a single exposure of the resist with $30 \mathrm{kV}$ electron beam energy. The gate pattern consists of three parts. The central pattern is a footprint and was a 1 pixel line. Two head patterns have a size of $200 \mathrm{~nm}$. The optimum conditions, to define T-shape gates at $150 \mathrm{~nm}$ level for pHEMTs were obtained when the footprint dose is $600 \mu \mathrm{C} / \mathrm{cm}^{2}$, the head dose is $140 \mu \mathrm{C} / \mathrm{cm}^{2}$. The top layer was developed in $1: 1$ mixture of MIBK:IPA for $60 \mathrm{sec}$ and then rinsed in IPA and blown dry in nitrogen. The second layer was developed in MF-319 developer and then rinsed in water. The third layer was developed for $30 \mathrm{~s}$ in MIBK: IPA $(1: 3)$ followed by rinsing in an IPA and blown dry with nitrogen.

Then recess etching was performed using citric acid based solution as an etchant to remove GaAs cap layer. After that T-gate metallization of Ti/Mo/Cu $(20 \mathrm{~nm} / 20 \mathrm{~nm} /$ $400 \mathrm{~nm}$ ) was deposited by e-beam evaporation under a vacuum of $5 \times 10^{-7}$ torr and lifted off in acetone. Finally, a layer of PECVD silicon nitride passivation was deposited; openings were etched in dielectric and the ohmic contacts were gold-plated for a good probe contact.

The device DC properties were measured with a Tektronix $370 \mathrm{~A}$. The microwave S-parameter measurements have been carried out by using a ZVA-40 network analyzer.

\subsection{Investigation of $\mathrm{Cu} / \mathrm{Ge}$ Ohmic Contacts Improvement. To} increase the specific contact resistance measurement accuracy in $\mathrm{Cu} / \mathrm{Ge}$ ohmic contacts formation experiments the Sidoped samples $n$-i-GaAs $\left(n=2 \times 10^{17} \mathrm{~cm}^{-3}, d=0.12 \mu \mathrm{m}\right)$ were used. For liftoff lithography process a mask based on two-layer $\mathrm{SiO}_{2}$ of thicknesses 0.3 and $0.5 \mu \mathrm{m}$ respectively was formed on the surface. The layers were deposited by plasmaenhanced CVD at different wafer temperatures. This enabled films to be formed with different etching rates and a hard mask for liftoff process. The openings in the mask of $\mathrm{SiO}_{2}$ were formed using etching in a buffer etching agent through the photoresistive mask. To remove the oxides of GaAs before deposition, the samples were treated in a $1: 10$ solution of $\mathrm{H}_{2} \mathrm{SO}_{4}$ for three minutes, followed by rinsing in de-ionised water and drying in a flow of nitrogen.

For deposition of the $\mathrm{Cu} / \mathrm{Ge}$ contact, the method of ebeam evaporation was used, with a residual pressure of $p$ less than $1 \times 10^{-6}$ torr. The thickness was $122 \mathrm{~nm}$ for the $\mathrm{Cu}$ film and $78 \mathrm{~nm}$ for the Gefilm. After the ohmic contact pattern was formed using the liftoff method a rapid thermal annealing of the samples was carried out. Annealing was performed ex situ in a single high-temperature stage in a inert environment at a temperature $T_{2}=440^{\circ} \mathrm{C}$ for a period of $t=60 \mathrm{~s}$. In the experiments with two-stage annealing the wafer, after treatment in $\mathrm{H}_{2} \mathrm{SO}_{4}$ solution, was divided into two parts, which were loaded into the vacuum chamber of the deposition unit. Films of $\mathrm{Cu}$ and $\mathrm{Ge}$ with an overall thickness of $200 \mathrm{~nm}$ were deposited on both wafers by the ebeam evaporation method under a vacuum of $5 \times 10^{-6}$ torr. The weight content of Ge in the two-layer composition was about $30 \%$. Then both wafers underwent preliminary thermal treatment in a single vacuum cycle at a temperature of $T_{1}=75^{\circ} \mathrm{C}$, one under vacuum, and the other in a flow of atomic hydrogen with a flow density of $10^{15}$ at. $\mathrm{cm}^{-2} \mathrm{~s}^{-1}$. The wafers were removed from the vacuum chamber and, after forming the ohmic contact pattern using the liftoff method, rapid annealing was carried out in an inert atmosphere at a 


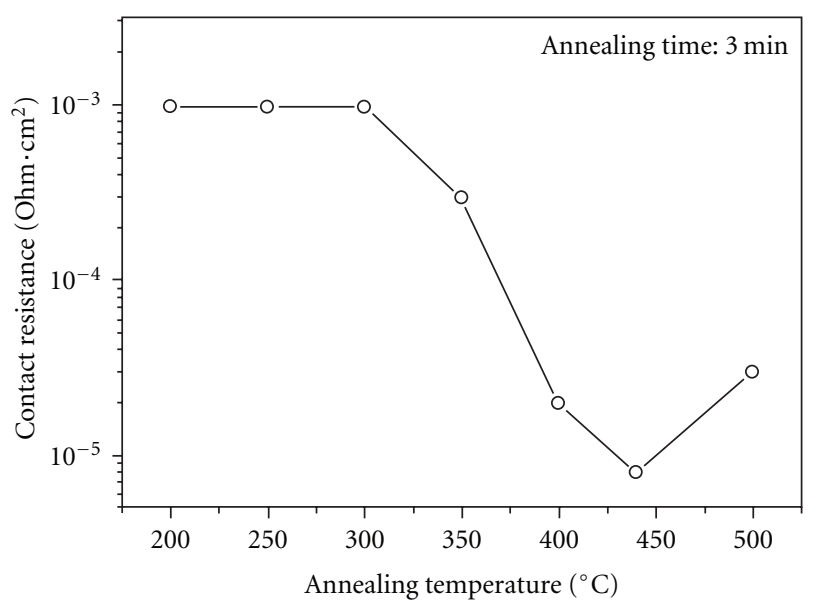

Figure 1: Dependence of the specific contact resistance of $\mathrm{Cu} / \mathrm{Ge}$ ohmic contacts to $\mathrm{GaAs} / \mathrm{AlGaAs} / \mathrm{InGaAs}$ versus the annealing temperature $(t=3 \mathrm{~min})$.

temperature of $T_{2}=80-460^{\circ} \mathrm{C}$ for a period of $t=60 \mathrm{~s}$. The process was repeated for preliminary annealing temperatures ranging from 100 to $400^{\circ} \mathrm{C}$ The two-layer $\mathrm{SiO}_{2}$-based hard mask was not lifted off. The specific contact resistance $\rho$ was measured using the transmission line method. Morphology of the contact surfaces was obtained using scanning electron microscope.

\section{Results}

3.1. The Cu/Ge Ohmic Contacts and T-Gate Fabrication. Figure 1 shows results of the specific contact resistance measurements of the $\mathrm{Cu} / \mathrm{Ge}$ ohmic contacts produced by ebeam evaporation and RTA annealed in inert environment.

The temperature dependences have a traditionally curves shape with the $\rho$ value minimum. With the annealing temperature raise the interdiffusion between multilayer metals film and GaAs is increased. This leads to a reduction of the specific contact resistance, down to minimum value of $\rho$. The subsequent growth of the temperature leads to $\rho$ increasing. It may be caused by the copper penetration from the top layer to the GaAs surface.

The minimal value of the specific contact resistance for $\mathrm{Cu} / \mathrm{Ge}$ ohmic contacts is $8 \times 10^{-6} \mathrm{Ohm} \mathrm{cm}^{2}$ after annealing at $T=440^{\circ} \mathrm{C}$ during $t=3 \mathrm{~min}$ in inert environment.

The Ti/Pt/Au Shottky contact on $n$-GaAs is the most widely used Shottky structure in the GaAs HEMT fabrication. In present study, the thick overcoat gold layer was replaced with copper. And Pt layer was replaced with the transition metal such Mo. The choice of the refractory metals was based on their resistivity and the capability as the diffusion barrier. The resistivity of Mo metal is much lower than of $\mathrm{Pt}$, therefore, the fabricated $\mathrm{T}$-gate $\mathrm{Ti} / \mathrm{Mo} / \mathrm{Cu}$ has a smaller gate resistance.

Figure 2 shows the SEM image of fabricated fully $\mathrm{Cu}-$ metalized pHEMT with $\mathrm{Cu} / \mathrm{Ge}$ ohmic contacts and the Tgate $\mathrm{Ti} / \mathrm{Mo} / \mathrm{Cu}$ with a length of $150 \mathrm{~nm}$.

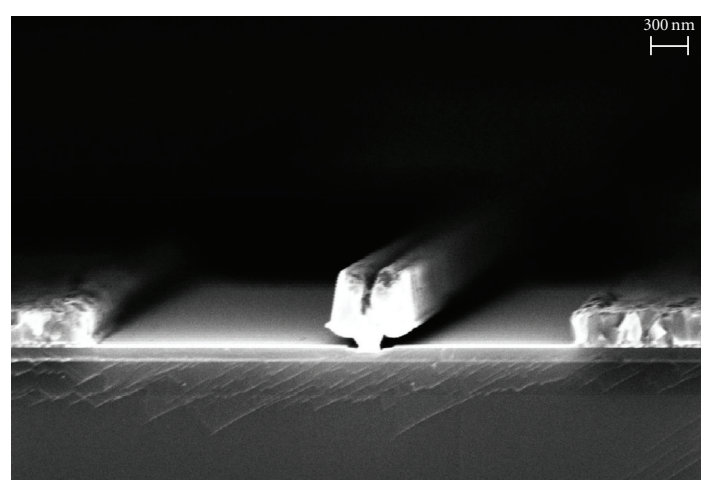

FIGURE 2: SEM image of fabricated fully Cu-metalized pHEMT with $150 \mathrm{~nm}$ T-gate $\mathrm{Ti} / \mathrm{Mo} / \mathrm{Cu}$.

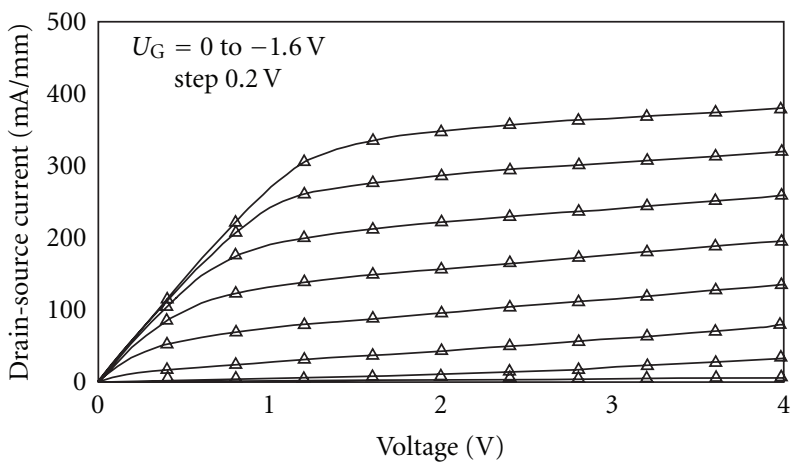

FIGURE 3: Current-voltage characteristics of the fabricated Cu-based pHEMT.

3.2. The Copper-Metalized pHEMT Performance. Figures 3 and 4 show the DC and RF characteristics of a fabricated fully $\mathrm{Cu}$-metalized GaAs pHEMT.

The device performance was measured for pHEMT with $150 \mathrm{~nm}$ gate-length and a total gate width of $100 \mu \mathrm{m}$. The fabricated $\mathrm{Cu}$-based pHEMT has a maximum drain current of $360 \mathrm{~mA} / \mathrm{mm}$, an off-state gate-drain breakdown of $7 \mathrm{~V}$, and a transconductance peak of $320 \mathrm{mS} / \mathrm{mm}$ at $V_{\mathrm{ds}}=3 \mathrm{~V}$.

The maximum stable gain value was about $15 \mathrm{~dB}$ at a frequency of $10 \mathrm{GHz}$. The current gain cutoff frequency of the copper-metalized device is about $60 \mathrm{GHz}$ at $V_{\mathrm{ds}}=3 \mathrm{~V}$ and maximum frequency of oscillations is beyond $100 \mathrm{GHz}$.

The DC and RF performance shows little difference between devices fabricated with copper and conventional AuGeNi based metallization.

\subsection{Investigation of $\mathrm{Cu} / \mathrm{Ge}$ Ohmic Contacts Improvement.} To study further improvement of pHEMT characteristics, $\mathrm{Cu} / \mathrm{Ge}$ ohmic contacts resistance minimization was investigated and the results are presented in the following.

Figure 5 shows the dependence of specific contact resistance $\rho$ on the temperature of preliminary thermal treatment $T_{1}$, carried out in situ under vacuum (1) and in a flow of atomic hydrogen (2) with a flow density of hydrogen atoms of $10^{15}$ at. $\mathrm{cm}^{-2} \mathrm{~s}^{-1}$. The second thermal treatment was carried out ex situ in an inert atmosphere at $T_{2}=440^{\circ} \mathrm{C}$ 


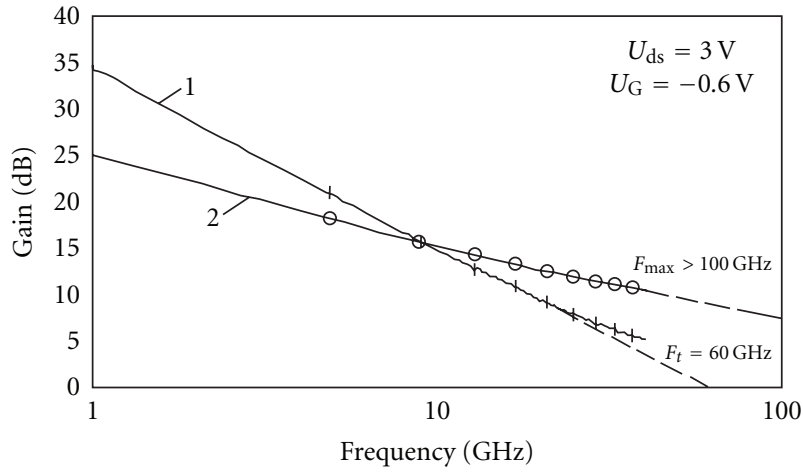

FIGURE 4: Measured current gain (1) and maximum stable gain (2) as a function of frequency of fabricated $\mathrm{Cu}$-based GaAs pHEMT.

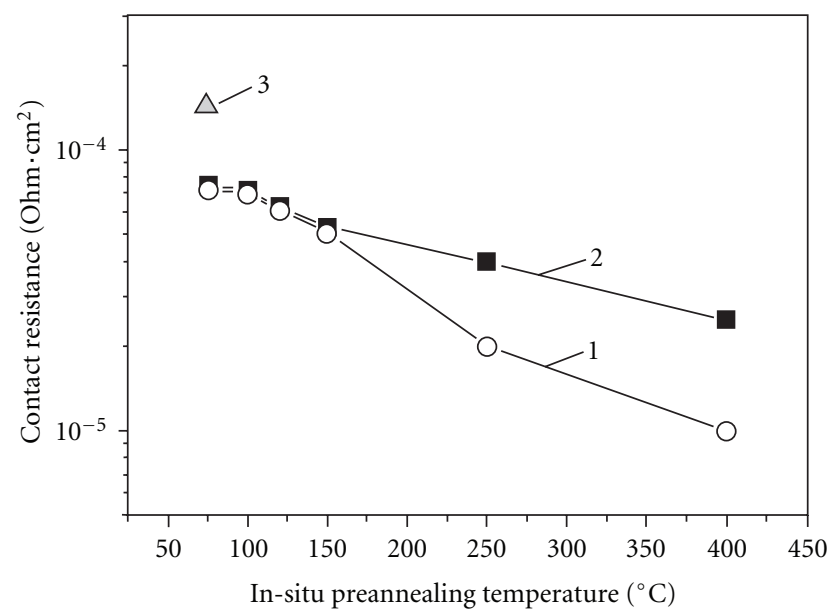

Figure 5: Dependence of specific contact resistance of $\mathrm{Cu} / \mathrm{Ge}$ ohmic contacts to $n$-GaAs on the temperature of preliminary thermal treatment $T_{1}$, carried out under vacuum (1), in a flow of atomic hydrogen (2) and without preliminary thermal treatment (3).

for $60 \mathrm{~s}$. At temperatures of the first annealing higher than $T_{1}=150^{\circ} \mathrm{C}$ for samples annealed in a flow of atomic hydrogen, smaller values of $\rho$ are observed than for samples annealed under vacuum. The difference of the values of $\rho$ for samples of both types increases with the temperature of the first annealing.

In Figure 6 SEM images are shown of the surface of ohmic contacts obtained using two-stage annealing under vacuum, and in a flow of atomic hydrogen at the preliminary in situ annealing temperature $T_{1}=400^{\circ} \mathrm{C}$. It can be seen that the samples which have undergone preliminary annealing in a flow of atomic hydrogen have smaller grain size.

As it is shown in [13] the annealing in atomic hydrogen has a significant influence on the microcrystal structure of the $\mathrm{Cu}$ film metallization, increasing the grain size, relative to annealing under vacuum. In the present study the reverse effect is observed in the $\mathrm{Cu} / \mathrm{Ge} / \mathrm{GaAs}$ system, which apparently is connected with the particular behaviour of solid phase reactions in a four-component system.

The minimum value of $\rho$ for a $\mathrm{Cu} / \mathrm{Ge}$ contact obtained using two-stage annealing at a temperature $T_{1}=400^{\circ} \mathrm{C}$

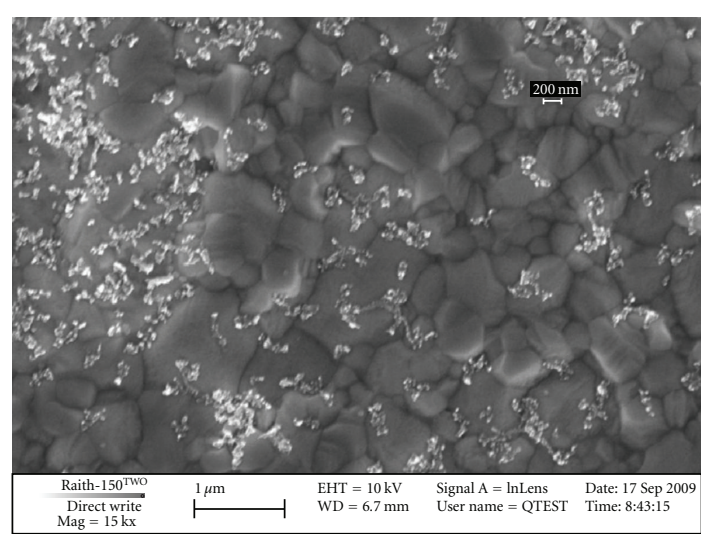

(a)

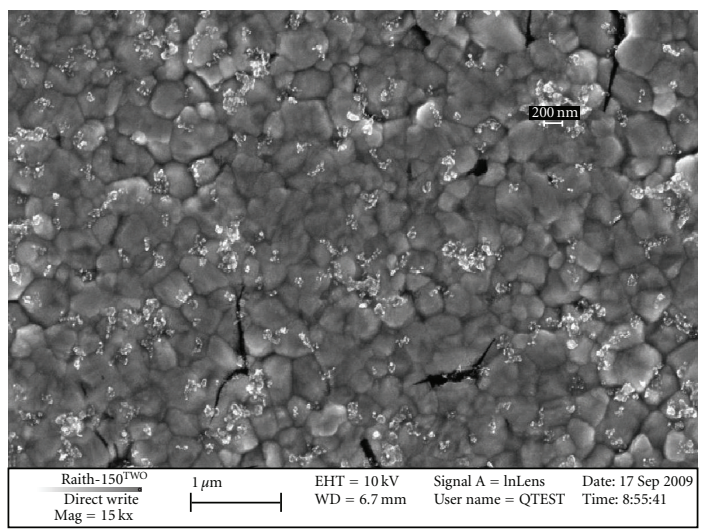

(b)

FIGURE 6: SEM images of the surface of ohmic contacts which have undergone thermal treatment at $T=400^{\circ} \mathrm{C}$ under vacuum (a) in a flow of atomic hydrogen (b); magnification 15,000x.

under vacuum and in a flow of atomic hydrogen is $2.5 \times$ $10^{-5} \mathrm{ohm} \mathrm{cm}^{2}$ and $1 \times 10^{-5} \mathrm{ohm}^{2}$, respectively. These values are significantly lower than the value characteristic of single-stage annealing ex situ of $1.5 \times 10^{-4} \mathrm{ohm} \mathrm{cm}^{2}$.

\section{Conclusions}

In this work the fully $\mathrm{Cu}$-based GaAs pHEMT with $\mathrm{Cu} / \mathrm{Ge}$ ohmic contacts and $\mathrm{Ti} / \mathrm{Mo} / \mathrm{Cu} 150 \mathrm{~nm}$ T-gate was successfully produced. The fabricated pHEMT has a peak transconductance of $320 \mathrm{mS} / \mathrm{mm}$ at $V_{\mathrm{ds}}=3 \mathrm{~V}$ and maximum drain current of $360 \mathrm{~mA} / \mathrm{mm}$. The maximum stable gain and current gain cutoff frequency were about $15 \mathrm{~dB}$ by at $10 \mathrm{GHz}$ and $60 \mathrm{GHz}$ at $V_{\mathrm{ds}}=3 \mathrm{~V}$, accordingly.

The possibility to improve the parameters of $\mathrm{Cu} / \mathrm{Ge}$ ohmic contacts to $n$-GaAs using two-stage annealing in the case when the preliminary annealing was performed at $T_{1}=150-400^{\circ} \mathrm{Cin}$ situ in a flow of atomic hydrogen with flow density $10^{15}$ at. $\mathrm{cm}^{-2} \mathrm{~s}^{-1}$ was demonstrated. Using such annealing enables the minimum value of contact resistance to be reduced by a factor of $2-2.5$ relative to preliminary 
annealing under vacuum, or by 2-15 times as compared to single-stage annealing in inert atmosphere.

\section{Acknowledgments}

This work was sponsored by the grant Carl Zeiss, Bortnik's grant U.M.N.I.K of Russia, and also by a grant of Tomsk administration. The authors wish to acknowledge the lab.7 staff of the Scientific and Research Institute of Semiconductor Devices Tomsk, Russia for support and also to the Scientific-Education Centre staff of the Tomsk University of Control Systems and Radio Electronics for microwave measurements.

\section{References}

[1] K. Holloway and P. M. Fryer, "Tantalum as a diffusion barrier between copper and silicon," Applied Physics Letters, vol. 57, no. 17, pp. 1736-1738, 1990.

[2] K. Holloway, P. M. Fryer, C. Cabral, J. M. E. Harper, P. J. Bailey, and K. H. Kelleher, "Tantalum as a diffusion barrier between copper and silicon: failure mechanism and effect of nitrogen additions," Journal of Applied Physics, vol. 71, no. 11, pp. 5433$5444,1992$.

[3] US Patent no. 0292785 A1, 2006.

[4] D. S. Yoon, H. K. Baik, and S. M. Lee, "Effect on thermal stability of a $\mathrm{Cu} / \mathrm{Ta} / \mathrm{Si}$ heterostructure of the incorporatio of cerium oxide into the Ta barrier," Journal of Applied Physics, vol. 83, no. 12, pp. 8074-8076, 1998.

[5] C. Y. Chen, L. Chang, E. Y. Chang, S. H. Chen, and D. F. Chang, "Thermal stability of $\mathrm{Cu} / \mathrm{Ta} / \mathrm{GaAs}$ multilayers," Applied Physics Letters, vol. 77, no. 21, pp. 3367-3368, 2000.

[6] C. Y. Chen, E. Y. Chang, L. Chang, and S. H. Chen, "Backside copper metallization of GaAs MESFETs," Electronics Letters, vol. 36, no. 15, pp. 1317-1318, 2000.

[7] C. Y. Chen, E. Y. Chang, L. Chang, and S. H. Chen, "Backside copper metallization of GaAs MESFETs using TaN as the diffusion barrier," IEEE Transactions on Electron Devices, vol. 48, no. 6, pp. 1033-1036, 2001.

[8] H. C. Chang, E. Y. Chang, Y. C. Lien et al., "Use of WNx as diffusion barrier for copper airbridged low noise GaAs PHEMT," Electronics Letters, vol. 39, no. 24, pp. 1763-1765, 2003.

[9] E. V. Erofeev and V. A. Kagadei, "A means of preparation of ohmic contacts to GaAs on the basis of thin films of Ge and Cu," Patent application no. 2009130823, 2009.

[10] M. O. Aboelfotoh, C. L. Lin, and J. M. Woodall, "Novel lowresistance ohmic contact to n-type GaAs using CuGe," Applied Physics Letters, vol. 65, no. 25, pp. 3245-3247, 1994.

[11] S. Oktyabrsky, M. O. Aboelfotoh, and J. Narayan, "Chemistry of Cu-Ge Ohmic Contact Layers to GaAs," Journal of Electronic Materials, vol. 25, no. 11, pp. 1673-1683, 1996.

[12] M. O. Aboelfotoh, S. Oktyabrsky, J. Narayan, and J. M. Woodall, "Electrical and microstructural characteristics of $\mathrm{Ge} / \mathrm{Cu}$ ohmic contacts to n-type GaAs," Journal of Materials Research, vol. 12, no. 9, pp. 2325-2331, 1997.

[13] C. S. Zhavzharov, N. Antonchenko, and V. Matyushin, "Modification of parameters of thin copper films under the action of atomic hydrogen," Visnyk of Lviv University, vol. 42, pp. 39-46, 2008 . 

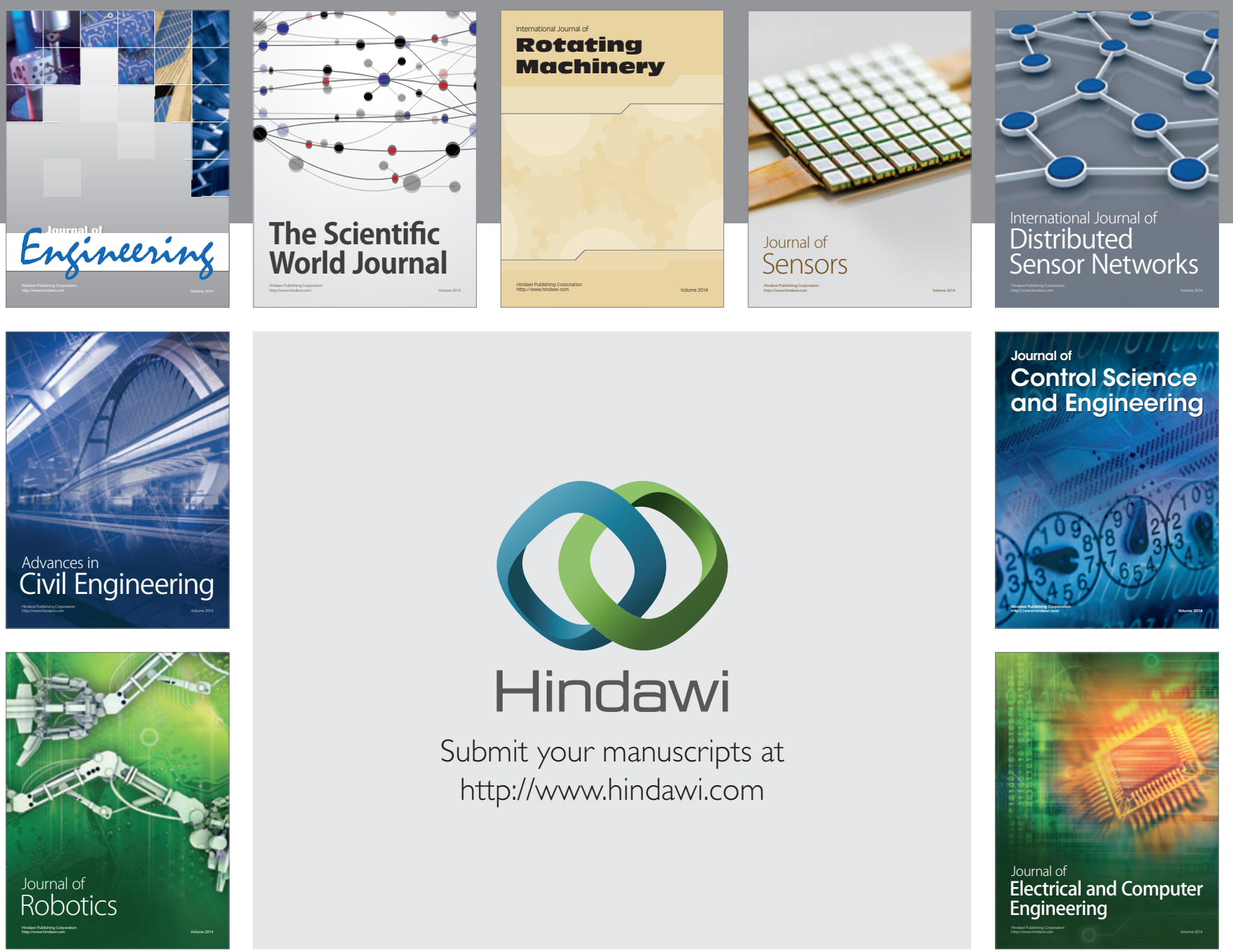

Submit your manuscripts at

http://www.hindawi.com
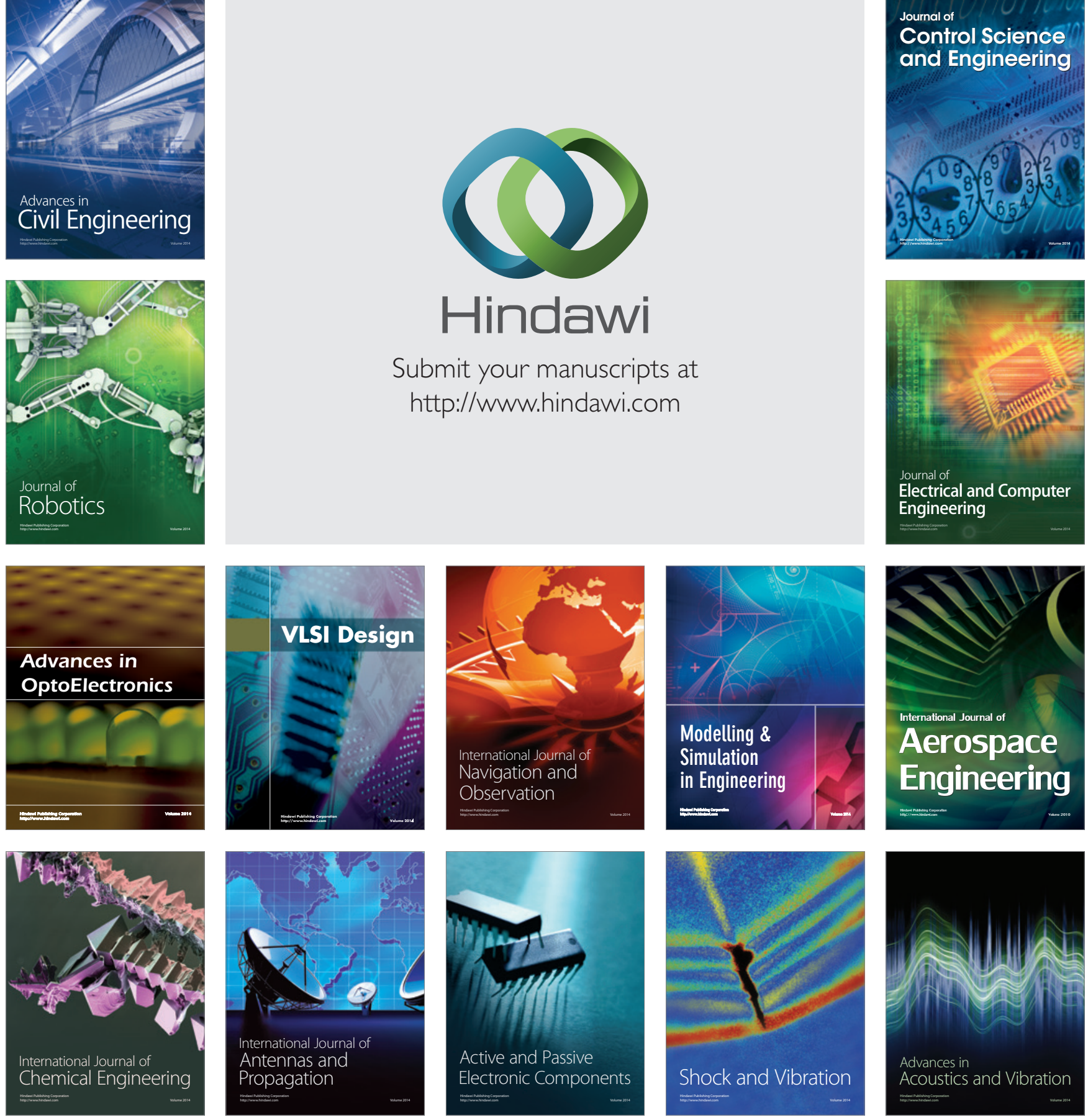